\title{
Analysis Of Human Resource Practices And Performance Of Immigration Department In Enhancing National Security In Kenya
}

\author{
Ms. Victoria K. Avoga*,Dr Isaac Mokono Abuga. Phd** \\ *Student, Department of Management, school of business and economics mount kenya university,Po Box 342-01000,Thika Kenya \\ ${ }^{* *}$ Lecturer Department of economics, school of business and economics mount kenya university,Po Box 342-01000,Thika Kenya \\ DOI: 10.29322/IJSRP.11.11.2021.p11926 \\ http://dx.doi.org/10.29322/IJSRP.11.11.2021.p11926
}




\begin{abstract}
The immigration department is very critical in the social, economic and political development of any country. This study was conducted to analyze how various human resource practices and performance of immigration department has influenced National Security in Kenya. The study further identified ways in which operations at the department can be improved and if this improvement can positively influence national security by reducing the number of cases of insecurity arising from entry and residence of illegal immigrants in Kenya. The study was conducted among immigration officers working at entry points of Jomo Kenyatta International Airport, (J.K.I.A) Busia and Malaba border controls. At the headquarters, the study was carried out at the Passports section, foreign national management section (F.N.M.S.) and the investigation and prosecution section (SEC/F) the target stations have a total population of 350 immigration officers. Out of this a sample was selected proportionally using stratified random sampling technique. In each stratum, $30 \%$ were selected randomly as respondents leading to a sample of 105 respondents being interviewed. Out of this sample, 98 respondents returned the fully filled questionnaires which accounted for 93\%. Data was collected using a self- administered questionnaire based on likert-scale which has five points range and few open ended questions. Analysis of the data showed that the selected human resource practices had a great role to play in improving performance at the immigration department, and the improved performance positively influenced national security by reducing numbers of illegal immigrants in the country. The study further revealed that the department had not properly implemented the human resource practices and that might be one of the key reasons why it had not been able to effectively play its securing the country from illegal immigrants. Finally the study recommends that if these human resource practices are properly implemented then the department can be very instrumental in enhancing national security.
\end{abstract}

Index Terms- Emigration, Immigration, National security, Performance Human resource

\title{
I. INTRODUCTION
}

$\mathrm{I}_{\mathrm{m}}^{\mathrm{m}}$ mmigration is the relocation to a different country with the intention of acquiring citizenship or permanent residence. These people move and settle or reside in the new country as naturalized citizens or permanent residents. There are also others who travel to foreign countries for short visits, meetings tourism and others.

According to Giovani, Levchenko and Otega (2015), "immigration equally benefits both the sending and receiving countries. Each of them benefits economically through the transfer of skill and or money". Studies have shown that elimination of immigration barriers can greatly impact on the country's GDP and that of the world at large. It is estimated that the world GDP gain ranges between 67 and 147 percent. (Clemens 2011). According to development economist, "reduced migration barriers can positively influence labour mobility between developing and developed countries and this will in return reduce poverty" (Clemens 2016).

In most countries immigrants have been blamed for increase in insecurity. Studies have indicated that in most of the developed countries, the rate of crime is higher among the migrants in comparison to the native populations. Warren and Tomaskovic (2009), but according to Ousey and Kubrin (2018), the relationship between immigrants and criminality may have been overestimated.

"Countries that have been hit by terrorist activities have more often discovered that the attackers or master minders are foreigners. This scenario has forced many countries to prioritize immigration matters when dealing with national security". (Stivatchtis 2008)

In Kenya, terror attacks have been on the rise especially from 2013 and most of these cases have been blamed on illegal immigrants (Agoya, 2013). This has in turn forced the Kenyan government to put more emphasis on the need to control illegal immigrants as a measure of enhancing national security.

Starting with the car blast at OTC in bus terminus in Nairobi in 1975 to the attack at Dusit D2 complex in January 2019 Kenya has reported over350 major terror attacks. The most notable cases being, 1st march 1975 car blast at OTC bus station killing 30 people, 31 st December 1980 Norfolk hotel bombing killed 20 people, 7th August 1988 U.S. Embassy bombing claimed 213 lives, 28th November 2002 Kikambala Hotel and Arkia Airline missile attacks killed 23 people, 21st September 2013 west gate mall shooting claimed 67 lives, 15th to 17th June 2014 Mpeketoni terror attack claimed 60 lives, April 2015 Garissa University shooting killed 150 persons and on 15th January 2019 DusitD2 complex attack claimed 21 lives Atellah (2019).

Acts of terrorism in Kenya have been steadily on the increase since 2011. During the period 2011 to January 2019 over 320 major attacks have been reported in the country with many other similar' incidences also being recorded over this period Atellah (2019).

In most of these cases, key suspects have been identified as foreigners who entered the country illegally and or held multiple identifications. (Agoya 2013) asserts that "though various government agencies are supposed to work towards ensuring safety and security of the country the immigration department carries more blame as the suspect enter the country through border points which they control".

Agoya's views are reinforced by The President remarks after the west gate terror attack where he expressly accused the immigration department and in particular the officers for working in collusion with the terrorists. (State House 2013) 
After every attack attention has been shifting on the immigration department and intensified crackdown on foreigners like the usalama watch of 2014 (Mohamed 2019). Apart from blaming the department little is done to find out why the department is unable to live to its mandate of securing the country against those foreign terror groups and networks.

Various studies have been done on contemporary threats to national security in Kenya. However little has been done in regard to the contribution of immigration department to national security. It is upon this background that this research seeks to examine the interplay between various organizational practices and performance at the immigration department in enhancing national security

\section{Research objective}

The main goal of this study was to investigate how the selected human resource practices influenced performance of immigration department and the influence they had in enhancing national security in Kenya.The study was guided by the following specific objectives.

i. Examine the influence of training on the performance of immigration department in enhancing national security in Kenya.

ii. Examine the extent to which monitoring and evaluation affect performance of immigration department in enhancing national security in Kenya.

iii. Investigate the effect of delegation on performance of immigration department, in enhancing national security in Kenya.

iv. Asses the influence of strategic partnerships on the performance, of immigration department in enhancing national security in Kenya

\section{Significance of the study}

Findings of this study will be expected to add to the body of knowledge on how the selected human resource practices could influence performance at immigration department and the influence it could have to national security in Kenya. The findings will also help different organizations such as IOM which are mainly concerned with issues affecting immigrants. And finally the findings will help the Kenyan security agencies and in particular the immigration departments on formulating policies that can improve its ability to counter cases of illegal immigrants who have been posing great danger to national security in this country.

\section{Scope of the study}

The investigator restricted the study to the immigration officers at all levels in the selected work stations. The target Stations being; Jomo Kenyatta International Airport (J.K.I.A.) Busia and Malaba border controls, Passport section, foreign national's management section (F.N.M.S), and the investigation and prosecution section SEC/F. These section were selected as a representative of all others.

Though cases of terrorism have been reported in the country since the seventies, there been a marked increase in the recent past. The study therefore focused on the period from January 2011 to January 2019. This period alone the country witnessed over 320 major attacks. Atella(2019)

After most terror attacks in Kenya accusing fingers have been pointing to foreigners as being the master minders, executors or financiers of these acts. The study will therefore focus on how the immigration department can contribute to national security in regard to detection and arrest of these foreigners who are either terrorist or sympathizers.

\section{Limitation of the study}

One of the limitation that was encountered while conducting the research was getting the respondents to respond to the research instruments during working hours as many of them were too busy serving customers as the immigration officers are mostly involved in front office services. Another major limitation was that the research was done under the COVID 19 protocols and restrictions. This made most of the respondents shy off from hard copies of the questionnaires. Finally, some of the information sought by this research was not in the public domain and therefore special request had to be made to access such information.

\section{Delimitation of the study}

The researcher prepared a self-administered questionnaire which she gave to the respondents to fill at their free time. Those not willing to handle hard copies were issued with the questionnaires through email which they filled and emailed back to the researcher. The researcher also made arrangement of meeting or communicating with the respondents through emails and phone calls to clarify on any issues and follow-up on the filled up questionnaires. Finally, the researcher used the research authorization permit to seek access for information that was not in public domain

\section{Assumption of the study}

The key assumption in this study is that most of the terrorist are illegal immigrants. It therefore follows that if the immigration department improves on some of its organizational practices, it will be able to control the entry and residence of illegal immigrants in the country. It further assumes that if illegal immigrants are controlled then cases of terrorism will reduce and this will positively impact on national security in Kenya. 


\section{LITERATURE REVIEW}

This study was supported by the theories and literature review of works done by different scholars on the same topic. This review is composed of two main parts namely: Theoretical, and Empirical reviews.

\section{Theoretical review}

This section looks at some of the theories which attempt to explain why people engage in different kinds of crimes despite their knowledge of the consequences of such acts to themselves and to others.

\section{Rational choice theory}

This theory was developed by Clarke (1997) in a bid to synthesize the constructs of previous studies that explains human decision making processes. Clarke argues that the rationality of means and end is the driving force in individuals and organizations arriving at decisions given choices. The theory posits therefore that behind every decision that individuals make in an organization, a set of choices have been reasonably analyzed based on costs of action and perceived benefits.

Clarke further explains that criminals for instance, make decisions based on bounded or limited rationality and as such, their actions are well calculated and deliberate. The offense actors consciously gauge the possibilities of a maximum gain out of their actions. Clarke also suggests that many lawbreakers make verdicts based on bounded or limited rationality. Limited rationality is the case in which an individuals or groups simplify a decision because of their inability to anticipate or consider all alternatives and all information. Bounded rationality on the other hand, is guided by emotions as the offenders are intellectually compromised. He suggests that sometimes emotional provocation may be very high at the moment of a crime making it hard for the perpetrators to control their rational considerations on the choices they make. The motivations for a criminal act therefore are cost and benefits associated with it. The economic benefits attached to it plus the risk of detection, determines the type of offence that is likely to be committed.

The theory underpins instances of instrumental crimes where an individual plan for a crime after weighing the risks associated with the offence. For instance, offences such as evading tax or corporate and fraud involves careful analysis of risks and benefits. Crimes that are driven by emotions such as premeditated murder are however are not explained by the theory.

\section{Empirical review}

This section examined studies and work by other scholar's researchers and commentators who have written on the influence of the various organizational practices and how they help the organization achieve its overall goal. The researcher assesses how the independent variables can contribute to the dependent variable which in this case is national security

Training, according to Edmonds (2010), is an organizational practice that aims to promote and sustain efficiency and effectiveness among highly motivated workforce and thus increase the profits. Global competition and technological development has in the recent years, greatly influenced training needs of different organizations. The current trends such as globalization and technological development have led to new challenges and market demands previously not experienced and therefore not adequately addressed by the educational and vocational curricular being offered. (Jiang, Lepak, Hu \& Baer, 2012).

Ombui (2014) established that, "training can mutually benefit both the employee and the organization". He observed that training enhanced the employee's motivation through skills which eventually influences personal self-esteem and performance as they become more confident in handling the assigned tasks. The organization on its part improve on the customer satisfaction which translates to more business from referrals of satisfied customers. The increase in the firm's profits boosts supplier confidence and are more likely to enhance their collaborations. The financial strength that the establishments boasts of impacts directly on reputation and can gain advance for better deals with her contractors.

Amin and Amen (2013), states that organizations that wants to optimize their employee's performance must invest heavily on professional development as it will impact their productivity and relevance. Most of the firms, invest in building new skills for their workforce through proper and long term planning of training schedules. This enables them to cope with the uncertainties that may arise in future.

Apart from imparting employees with the correct skills, trainings also encourage competition among them. The variations between the expected and actual performance among the workforce is greatly reduced through constant coaching and mentorships programs. This also promote the spirit of teamwork and hence confidence and motivation aspects are greatly boosted. As a result, the organizational goals are achieved (Tai2006).

In Kenya the public service has not been very keen on training the staff in some cases, an employee might join the service and serve till retirement age without undergoing any skills upgrading programme. (Mbijjiwe andVenkataiah2013).

Mbijjiwe and Venkataiah (2013) noted that, some departments in public service do not hold formal induction courses as new employees are expected to learn from the older ones who not only pass on outdated skill but also the vices making underperformance an endemic in the Kenya's public sector. It is therefore necessary to establish protocols that induct the newcomers in a formal manner where they get introduced to organizational structures, cultures, leadership, resources and responsibilities. The public service has experienced the trickle down impacts of non-induction procedures to new employees as they have witnessed high cases of strikes, damages, poor service delivery, high turnover and incompetence among the personnel who are not introduced to the organization properly. This indicates that professional development is crucial for achieving efficiency, performance and outputs. 
An examination report on policies, systems practices and procedures at the department of immigration by the Kenya anticorruption commission, revealed that most immigration officers have only gone through induction course. The few who have undergone other course noted that the courses are not tailored to the emerging national security threats which they are supposed to address. The report further noted that most immigration officer were not equipped with the right skills to handle emerging issues of terrorism and human trafficking (KACC 2006).

Lack of proper training at the immigration department has led to under performance of the department. A report by United States Department of State (USDS 2017) notes that despite the installation of personal identification secure comparison and evaluation (PISCES) at all entry points in Kenya, this system which can identify all watch listed person was not frequently used as some offices were not trained on how to use it effectively. This is a loophole which terror suspects have often exploited to gain access to the country, the report added. IOM (2018) observed that the organization has tried to equip the immigration department with modern technology to fight terrorism. However little has been achieved as most officers seemed to be ill trained on emerging immigration trends. The report recommended for tailored immigration trainings through the better migration management (BMM) which can adequately address the emerging security threats.

According to the International Monetary Fund (IMF 2015a) Monitoring and Evaluation Systems is a tool that is used by both the private and public sector to accurately assess and measure the output and performance and of each individual employee. These measures in turn enhances accountability, effectiveness, and efficiency of the individual staff and also that of the entire organization which translate to the realization of Sustainable Development Goals (SDGs).

Evaluating and monitoring staff performance in the Kenyan public sector was borrowed from the private sector. It was aimed at enhancing productivity of the public sector workers in keeping up with the global changes that had given rise to more citizenry awareness and demand for better services.

"The introduction of performance contracting in the public service was aimed at improving service delivery and at the same time impart new culture of pragmatism and innovation that centers around addressing customer needs, enhancing outputs and impact" (GOK 2003).

"The Kenyan government introduced Result Based Management (R.B.M.) which is a participatory and team based management tool designed to achieve defined results. These results could be achieved through proper planning, programming, management efficiency, effectiveness, accountability and transparency. Such could only be achieved through continuous monitoring and evaluation of staff and using the feedback to improve on service delivery" (CIDA, 2001).

The performance appraisals in Kenya public sector are usually done on quarterly basis. This means that each government institution is required to submit their quarterly reports and finally annual report to their respective supervisors. The supervisor will after reviewing the performance sends back feedback with comments which the respective institution is supposed to use to improve on its output or performance. Basing on the institutions strategic plan. Each institution develops an implementation matrix by which it outlines the timeframe and resources required to accomplish each targeted activity. This process in turn trickle down to individual employees who are required to be apprised monthly, quarterly and then annually" (OPM 2010)

The main assumption that drives the idea of monitoring and evaluation is that 'once performance can be measured, then it means that shortfalls can be identified (including non-performers). This in return informs on the decisions to be taken to address the shortfalls. Monitoring and evaluation, is therefore based on the premise that objectives that are set, produce tangible and measurable results which have impact on the populace. Moreover, the process is meant to flag off weaknesses and failures are offer effective interventions. It should therefore be used to continuously bring changes that address the shortfall that have been identified in most government institutions (Obong'o, 2009), Mutinda, (2017) argues that, staff appraisal can only be beneficial, if the following approaches are adopted: political and bureaucratic support at the highest levels; having clear and well defined guidelines which are reviewed continuously to incorporate experiences, lessons learnt and new developments. The staff should not be involved only in setting target but also in analysis of the feedback so as to get the most valued experiences which can enhance their performance.

In most public institution in Kenya, Monitoring and evaluation has not been effective in improving performance because it is viewed as a foreign culture which was borrowed from the private sector. Also feedback is rarely used to inform decision making. Another major problem is that appraisal is done as a routine practice rather than a tool to measure the institutions and individual staff performance so as to make informed decision and changes that can lead to improved performance" (GOK 2012).

The Kenya anti-corruption report on immigration department, noted that RBM had not been properly implemented in the department as the policy frame work for setting targets and analyzing achievements was not clearly understood by most supervisor. This scenario reduced the appraisal process to a routine rather than a tool to measure each staff's performance in relation to efficiency, effectiveness, accountability and transparency. (KACC 2006).

Since its inception in 2004, performance contracting has not yet achieved its intended goals. Kobia and Mohammed, (2006), opines that despite the radical changes being implemented in all departments across the public service, the enhanced service delivery has been witnessed more in the immigration department, registration of persons provincial administration, internal security, health, finance and water. This indicates that the fundamental changes in the government ministries has not translated into expected results across them and only a handful have managed to register growth. 
Schultz, Bagraim, Potgieter, Viedge and Werner (2003) states that, delegation is a mechanism of involving employee in decision making. This enhances their sense of responsibility and involvement which in return leads to positive achievement of the organizations goals. According to them delegation has a motivating effect and make employees improve their performance

According to Seibert, Wang, and Court right, (2011) "delegation is applied where the employer belief that the employee has the ability to make decisions, be responsible for their actions, and results of their actions can be measured" They further allude, "that through delegation an employee is viewed as a thoughtful human being who can positively contribute to the wellbeing of the organization, and not just a pair of hands doing what others say". This brings about a feeling of job ownership and commitment.

Carol (2002), further states that, delegation is designed to cascade downward the process making decision to lowest level possible. Every employee in any organization regardless of their levels has a role to play in helping the organization achieve its goals. Organizations that have developed a culture of delegation, facilitate employees at each level to get the clear vision of the organization, and strive to equip them with right information that is sufficient for them to make right decision and achieve the organizational goals at their levels. Employees who are well empowered to make decisions become confident in handling problems within their levels without necessarily seeking assistances from their seniors.

When employees contribute in the decision making processes regarding assignments and tasks, the degree of ownership is improved and thus take responsibility for products and services they produce. "Lack of proper delegation policy at the department makes the senior officers to be held accountable for mistakes done by their juniors. This has made the junior officers engage in corrupt practices as they are rarely held accountable for their actions" (KACC 2006).

Delegation can be effective when the organization encourages its employees to design own goals and outcomes in line with individual capabilities. This embed confidence and recognition as the establishment values individual initiatives in attainment of organizational goals. Such entrustments promote continuous career development as it stimulates innovation and creativity and thus enhance performance and prudence in utilization of resources. As a result, the spirit of self-determination and better performance of tasks is achieved (Carol, 2002) Hashem et. al, (2013) conducted study on the impact of structural empowerment in achieving psychological empowerment. The study found out that, "there is a statistical significant between availability of structural empowerment that is, delegation authority to staff at the front line of operation to make some decision without necessarily consulting the superior and improved performance". The study also noted that, "personality development, participation and development of innovative behavior creates an awareness that one holds an important and meaningful job position which he must be accountable for the action he takes".

The Kenya anti-corruption report on immigration noted that inability of line immigration officers to make decision created room for corruption. Holding Suspect for many hours at point of entire while awaiting guidance from the head office exposed the line officers to being compromised by the suspects. This has led to cases of suspect disappearing mysteriously some of who later turn to be criminals or traffickers. (KACC 2006)

Strategic partnership is characterized by a common arrangement between two or more organizational units with a view of improving outcomes and impacts. The parties agree to share and integrate resources, ideas and information for maximum outcome that benefits both independently. The arrangements are intended to go beyond individual abilities and as such, produce immeasurable results (COPAC, 2000).

The international organization for migration (IOM) noted a big gap in the partnership forged between various government agencies dealing with security in Kenya. In their 2017 report they noted that sideling the immigration department in national security matters was creating a missing link in the war against terrorism, as most terror attacks had been masterminded or executed by foreigners whose management is mainly a function of this department. In this report, they specifically singled out the amended sections of the Security Laws Act (2014). The segments intended to seal the loopholes and reinforce the nation's legislative agenda in countering terrorism activities. New initiatives such as trainings in terrorism and coordinated border patrol in addition to national counter terrorism unit were established. The act incorporated all the counterterrorism activities performed by security agencies in charge of national (National Police Service) and international (Kenya Defense Force) borders as well as intelligence (National Intelligence Service) and did not mention immigration department which deals with issues of citizenship.

Security interagency coordination in Kenya efforts and border control strategy, has been facing several challenges. Gaps in border security management arising from uncoordinated operation by various security organs at border points has made it possible for potential terrorists to sneak in and out of the country without being traced. Moreover, the efficacy of screening infrastructure at the points of entry has been greatly compromised due to operational bottlenecks. Also sharing of information and taking proper course of action is not well coordinated as the various agencies seem to operate in isolation (IOM, 2016)

An assessment done by 1.O.M involving institutions with border management functions and the relationships between these institutions; in Nairobi, Mombasa, Namanga, and Busia; points of entry discovered that though there existed consultative committees, inter- ministerial agreements, and consultative processes; the internal organizations structures within key department and the different command structure within each department greatly hampered effective and fruitful cooperation in border management. (IOM, 2016)

Inadequate or uncoordinated information sharing and poor cooperation among Kenya's security agencies can to a large extend be blamed for the raising rate of insecurity. "The intelligence and security forces may not be able to avert bloody attacks like the one witnessed at Westgate shopping mall because the police officers are easily bribed, and also there is supremacy battles among various government agencies that hinders information sharing and cooperation. Some of the rivalries that hinder intelligence gathering emerged while 
the assault on the west gate mall was underway. The police and Kenya defence forces seemed to try to outdo each other giving the attackers an easy time to escape. (Blair, 2013)

Hope (2018) note that the bureaucratic bottlenecks has hindered greater corporation among departments in charge of security, thereby jeopardizing the national security efforts in combating extremisms. Sharing of vital terror- related information between agencies is hampered as they continue to work independently. Experts claim these operational units perceive others as rivals and not partners and thus cannot function efficiently, further aggravating the security menace that is posed by immigrants

\section{Conceptual framework}

This is a framework or diagrammatic presentation showing interrelationship between the independent and dependent variables. According to Mugenda and Mugenda 2003, "conceptual framework is a working definition of variables and enables a simple explanation of the flow of theoretical framework used by the study". The main variable for this study is performance at immigration department as the dependent variable which is being influenced by organizational practices i.e.; training, monitoring and evaluation, delegation and strategic partnership at the immigration department.

\section{Independent Variables Intervening Dependent Variables}

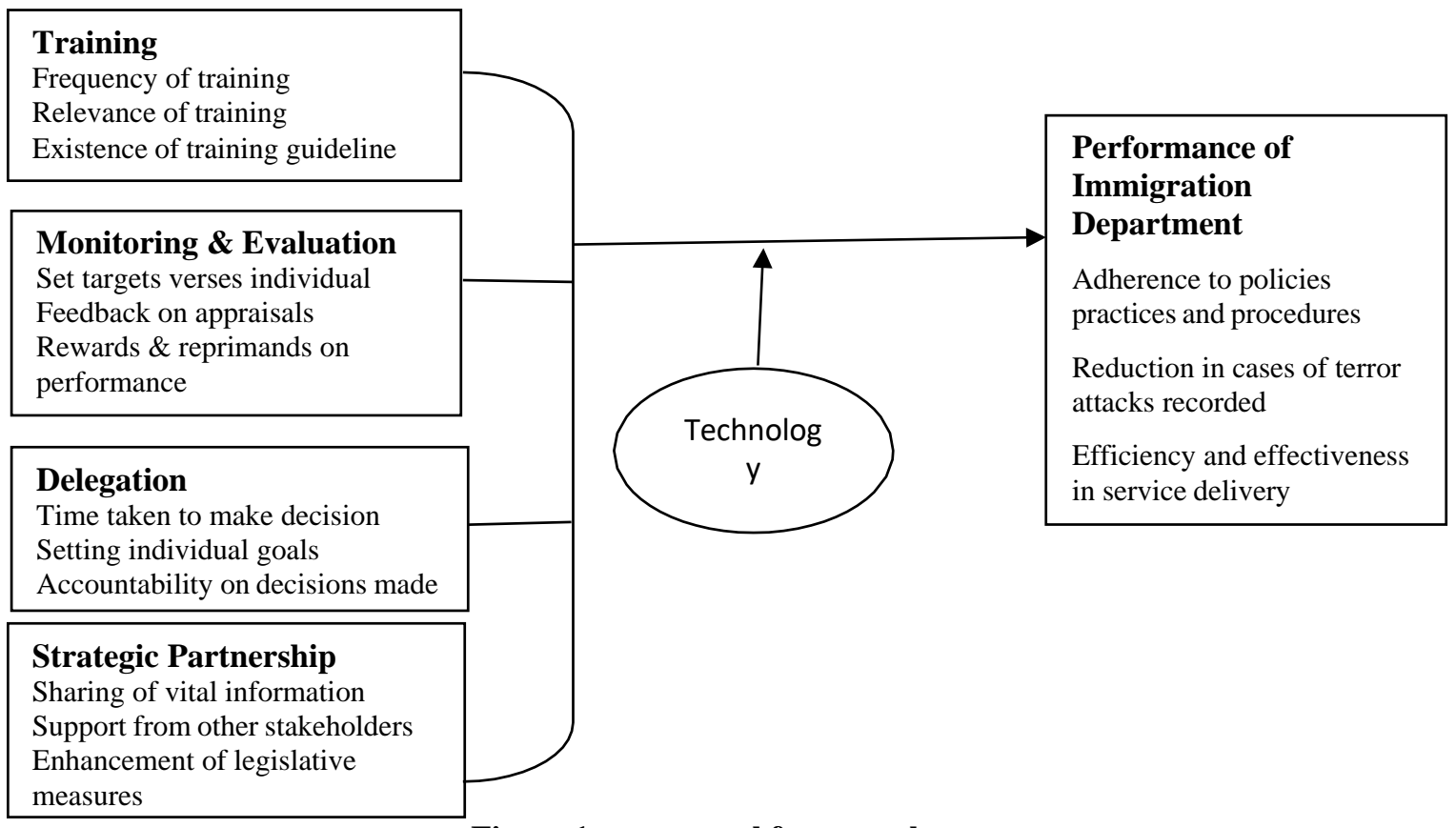

Figure 1: conceptual framework

Source: Researcher 2021

From this study performance of the immigration department has a great influence on the status of national security in Kenya. When the performance is improved then the incidences of illegal immigrants will greatly reduce and this will positively impact on the state of security in the country. According to this study performance can be improved if the organizational practices are well implemented.

Training is a key organization practice which according to many empirical studies has been responsible for improved performance in most organizations. Training helps equip the staff with new knowledge and skills to be able to cope up with the changes in the working environment. Changes can either be internal, external environment and for any organization to adopt to these, it must have a well formulated and coordinated training program which addresses the changes.

The study also proposed that monitoring and evaluating staff performance can improve the overall department's performance. However, the individual set targets must be in line with tyhe overall organizations target this will ensure that positive individual performance 
definitely translate to the organizations improved performance. The study also suggests that the appraisal should not be done as a routine program but as a means of getting feedback which can be used to improve on systems and procedures to produce better results

Delegation is another organizational practice that the study felt could greatly influence performance. By giving the staff an opportunity to make decisions on how best to perform the assigned task, the staff gets more ownership of the task which more often leads to better performance. Delegation also improves service delivery by reducing time taken to solve some cases.

Finally, strategic partnership between the department and other government or non- governmental organization can improve performance greatly. The partnership involves sharing of vital information and executing some decisions. The study observes that security is a complex issue and always needs a multi sectoral approach to be handled effectively. However, this cooperation should be done in an environment devoid of completion and mistrust.

\section{Research Gap}

Most of the studies that have been done on organizational practices have been focusing on performance of organizations in the private sector. This may have been informed by the fact that for a long time most public sectors and especially those dealing with security were more concerned with implementing government policies rather than offering services.

From the beginning of this centaury the government also felt the citizens pressure of requiring better services and other emerging trends like increased cases of insecurity made the government change its approach in service delivery and adopted the result based management. This approach lead to importation of most management systems from the private sector among them is the organization practices that this study focused on.

The practices are mostly copy pasted from the private sector and very little has been done to study the effectiveness of this practices in the public sector. The information avillable is mostly from the private sector because the practices have been there for long but for the public sector there is a huge gap which this study has tried to address.

\section{RESEARCH DESIGN AND METHODOLOGY}

In order to satisfy the objectives of this study, the researcher adopted a quantitative research methodology. This method according to Corrine (2011) is the most appropriate in natural and social sciences because it employs mathematical models to measure relationship between different variables and statistically present data collected using specifically design measuring tool to represent this relationship. By adopting quantitative method, the researcher was in a position to statistically test the relationship between the independent and dependent variable. The results were then graphically presented using tables, graphs and pie charts. Since the researcher used 1-5 likert scale questionnaire, this method was the most appropriate to apply in this research to collect the data.

The data collected using the 1-5 likert scale questionnaire is normally in numbers this made it more accurate to analyze as the respondent's views were restricted to test what the researcher intended. It also made the researcher remain objective and even the respondents as it eliminated personal feelings and emotions. Finally, this type of questionnaire was easy to answer and therefore convenient for this study because most of the respondents were mostly engaged in front office duties and hence had very limited time to answer the questionnaire,

The target population comprised of immigration officers working at J.K.I.A, Busia and Malaba border points, Passport section, and foreign national management section (F.N.M.S.) and the investigation and prosecution section. (SEC/ F) The study focused on employees from all levels in the selected stations. This was done through stratified random sampling in which $30 \%$ was sampled from each category. The total population under study comprised of 350 immigration officers who were distributed in the selected stations according to their ranks as shown in table 1

Table 1: Sample size

\begin{tabular}{|l|l|l|l|}
\hline Category & Population frequency (N) & Sampling ratio (\%) & Sample (n) \\
\hline Deputy Director of Immigration & 4 & 30 & 1 \\
\hline Ass Director of Immigration & 10 & 30 & 3 \\
\hline Principal Immigration Officer & 73 & 30 & 22 \\
\hline Senior Immigration Officer & 126 & 30 & 38 \\
\hline Immigration Officer I & 137 & 30 & 41 \\
\hline Total & $\mathbf{3 5 0}$ & $\mathbf{3 0}$ & $\mathbf{1 0 5}$ \\
\hline
\end{tabular}

Source: Researcher 2021

\section{Data analysis techniques and procedures}


The collected facts and figures were arranged into sub-categories, cleaned and corrected in order to eliminate outliers. The Pearson product correlation coefficient was used to measure the level of affiliation between the response and predictor variables. The formula below helped the researcher to gauge the coefficient $r$

$$
r=\frac{n \sum x y-\left(\sum x\right)\left(\sum y\right)}{\sqrt{n\left(\sum x^{2}\right)-\left(\sum x\right)^{2}} \sqrt{n\left(\sum y^{2}\right)-\left(\sum y\right)^{2}}}
$$

In this equation, $\mathrm{r}$ represents the strength of the relationship between the dependent and the independent variables, with $\mathrm{x}$ representing the values of the independent variable and y representing the values of the dependent variable.

Multiple regression analysis was used to calculate the relationship between the independent variables which in this case were the organizational practices, and the dependent variable which in this case is performance at the immigration department. To calculate this relationship, the multiple regression formula:

$Y=\beta_{0}+\beta_{1} X_{1}+\beta_{2} X_{2}+\beta_{3} X_{3}+\beta_{4} X_{4}+\varepsilon$ in which; $Y=$ performance of immigration department $X_{1}=$ Training

$\mathrm{X}_{2}=$ Monitoring and evaluation $\mathrm{X}_{3}=$ Delegation

$\mathrm{X}_{4}=$ Strategic partnership

$\beta_{0}=$ Is a constant (which is the value of dependent variable when all independent variables are zero)

$\beta_{1-4}$ is the regression coefficient or changes introduced by $X_{1}, X_{2}, X_{3}$ and $X_{4}$

$\varepsilon=$ Error term

$\mathrm{Y}=$ dependent variable, $\mathrm{X} 1, \mathrm{X} 2, \mathrm{X} 3, \mathrm{X} 4$, = independent variables, a = interceptor, b, c, d, e, $=$ slopes and $€=$ residual (error).

Finally, Statistical tools and techniques such as frequency analysis tables, graphs and charts among others will be used to present the data. It is then from this data that analysis will be made to come up with meaningful results and conclusions.

\section{Ethical issues}

The researcher applied for a research permit from the ministry of education science and technology, through the coordinator of postgraduate studies, school of business and economics Nairobi campus. All these are annexed in the appendices. The researcher $\backslash$ then introduced herself to the research subjects using the introduction letter annexed as appendix

The researcher assured the research subjects that the research was purely for academic purpose and that participation was voluntary and that there was no any danger in participating.

The respondents were also informed of their right to withdraw at any time during the study and or share what they were comfortable with. All information collected was treated with utmost confidentiality. And all findings of this study will be used purely for academic purpose. After analysis the questionnaire were shredded and completely destroyed to ensure confidentiality.

\section{DATA ANALYSIS, FINDINGS, AND INTERPRETATION}

\section{Reliability Test}

Reliability test gives an explanation how internal consistency was achieved. The researcher used the Cronbach's alpha test to form the consistency of the measuring instruments over the various inquiries on the survey. This was ensured by acquiring the Cronbach's alpha $(\alpha)$ by relating the questions in the survey.

Information was gathered by administering the tool to a five immigration officers randomly selected from three different sections at the headquarters. The data collected was the analysed for dependability. The results are indicated in table 3

Table 3: Total Statistics Analysis

\begin{tabular}{|ll|}
\hline Study items & Cronbach's alpha if item deleted \\
\hline National security & 0.658 \\
Training & 0.890
\end{tabular}




\begin{tabular}{|ll|} 
Monitoring and evaluation & 0.740 \\
Delegation & 0.713 \\
Strategic partnership & 0.880 \\
\hline Cronbach alpha $=\mathbf{0 . 8 8 7}$ & No of items $=\mathbf{5}$ \\
\hline
\end{tabular}

Source: Researcher 2021

These results show that the reliability alpha of 0.887 portrayed a high consistency of the tools. According to Kothari (2012), the consistency is high if $\alpha$ is equal or more than 0.7. In this case $\alpha$ is 0.887 and this means a high consistency leading to the retention of each of the items in the study

The findings as indicated in table 3 shows that, removal of training in the study could have raised the consistency to 0.890 while removal of monitoring and evaluation could have lowered the consistency to 0.740 . if delegation was omitted, the consistency could reduce to 0.713 while removing strategic partnership could reduce the consistency to 0.880 .

Based on this finding the researcher opted to retain all the items as $\alpha=0.887$ was an indication of a high internal consistency and this meant that the questionnaire was sufficiently reliable.

\section{Validity Test}

Validity test measure how much scores from a measure represents what they should gauge. Content validity test was utilized to evaluate whether the questions in the survey represented the particular organizational practice as was conveyed. The researcher got advice from the supervisor and also sought opinion from some immigration officers on how well the questions were provoking the research subject for the response to connect the dependent and the independent variables. These remarks and suggestions were analyzed and appropriate changes made to ensure validity of the instrument

\section{Response Rate.}

The study targeted a sample of 105 immigration officers working in different stations at the headquarters and selected border as respondents. However, out of 105 questionnaires distributed, 98 respondents completely filled in and returned the questionnaires, contributing to $93 \%$ response rate. This is indicated in table 4 This is a reliable response rate for data analysis as Mugenda and Mugenda (2003) pointed out that for generalization, a response rate of 50\% is adequate for analysis and reporting. $60 \%$ is good and a response rate of over $70 \%$ is excellent.

Table 4: Response Rate

\begin{tabular}{|lll|}
\hline Response & Frequency & Percentage \\
\hline Filled in questionnaire & 98 & 93 \\
Un returned questionnaires & 7 & 7 \\
\hline Total & $\mathbf{1 0 5}$ & $\mathbf{1 0 0}$ \\
\hline
\end{tabular}

Source: Researcher 2021

\section{Performance of Immigration Department and National Security.}

The study sought to establish how the various organization practices had influence the overall performance of the immigration department and the extent to which this performance has impacted on the state of national security in Kenya. The data was gathered using a 5 point Likert Scale questionnaire (range from 1 to 5), which was moderated to yield statistics shown in Table 2 
Table 2: Performance of Immigration Department and National Security

\begin{tabular}{|lll|}
\hline Performance of immigration department on national security & Mean & Std Dev \\
\hline Collaboration with other agencies has increase number of terrorist arrested & 3.87 & 1.12 \\
Involvement of the department in security meetings can reduce terrorism & 4.01 & 1.06 \\
Most of the terror activities are financed and executed by illegal immigrants & 3.90 & 1.22 \\
Improving immigration operations can prevent many terror activities & 3.88 & 0.97 \\
Reduction in terrorism can be attributed to improvement at immigration & 2.87 & 1.14 \\
Immigration department is responsible for insecurity caused by foreigners & 2.58 & 0.95 \\
\hline Average contribution of immigration department to national security & $\mathbf{3 . 5 2}$ & $\mathbf{1 . 0 8}$ \\
\hline
\end{tabular}

Source: Researcher 2021

The above results mean of 3.52 and a standard deviation of 1.08 indicates that the respondents generally agreed that performance of the immigration department had a key role to play in enhancing national security in Kenya. At a mean of 4.01 and standard deviation of 1.06 the responded agreed that involving immigration department at security meetings could greatly contributed to reduction of terror attacks in the country.

They also agree that the number of terror suspects being arrested has increased due to collaboration between immigration department and other security agencies, this was at a mean of 3.87 and a standard deviation of 1.12. in addition, at a mean of 3.90 and standard deviation of 1.22 the respondents were in agreement that most terror activities witnessed in the country since 2013 have been planned financed and executed by foreigners who were in the country illegally. There was also an agreement that improving immigration practices can help to stop terror activities as most of the suspects can be arrested before executing their mission.

The study also noted that at a mean of 2.87 and standard deviation of 1.14 the respondents were uncertain on whether the observed reduction of terror activities was as a result of improved operations at the immigration department. Finally, the study observed that at mean of 2.58 and standard deviation of 0.95 , the respondents were uncertain on if the immigration department should bear the responsibility of security breaches caused by foreigners

The study went further to establish the extent to which each independent variable influenced the dependent variable. The outcome was gathered utilizing a 5 point Likert Scale questionnaire (range from 1 to 5), which was moderated to yield statistics interpretation as shown in Table 6

\section{Training at Immigration Department of National Security}

The analysis evaluated the first objective which aimed at Examining the influence of training on the performance of immigration department and its influence to national security in Kenya, the results are shown in table 3

Table 3: Training at Immigration Department of National Security

\begin{tabular}{|lcc|}
\hline Training at immigration in relation to performance and national security & Mean & Std dev \\
\hline Regular evaluation of external environment to determine training needs & 3.85 & 1.01 \\
Changes in strategic goals often informs on the training needs & 3.68 & 1.13 \\
Training needs reflect skill deficiencies necessitated by changes in environment & 3.73 & 0.94 \\
Training offered are meant to equip staff with skill to make the more effective & 3.37 & 1.22 \\
Training informed by the changes in environment has improved performance & 4.01 & 1.12 \\
\hline Average influence of training on performance and national security & $\mathbf{3 . 8 0}$ & $\mathbf{1 . 0 8}$ \\
\hline
\end{tabular}

Source: Researcher 2021 
The respondents at a M 3.08 and SD1.08 shows that they agreed that training had an influence on the departments performance and hence national security. It further showed that they agreed (M3.85, SD1.01) that evaluation of external environment to determine training needs will influence performance. They also agree that setting training needs in line with strategic objective will improve performance (M 3.68 SD1.13). They also agreed that when needs are informed by deficiencies caused by change in environment it will influence performance (M3.73, SD 0.94). The respondents further agreed that when trainings are geared towards giving the right skill there will be a positive influence on performance (M3.37 SD1,22). Finally, the respondents agreed that when training is informed by changes in the working environment the performance will improve (M4.01, SD 1.12).

\section{Influence of Monitoring and Evaluation on Performance}

On the second objective where the study was investigating the influence of monitoring and evaluation on performance at the department of immigration the results are shown in table 9

Table 9: Influence of Monitoring and Evaluation on Performance

\begin{tabular}{|lcc|}
\hline Influence of Monitoring and Evaluation on Performance & Mean & Std dev \\
\hline Frequent monitoring and evaluation has a positive influence on performance & 2.87 & 0.96 \\
Strictly following clear guidelines during M\&E influences performance positively & 3.37 & 1.03 \\
Using feedback from M\&E to bring operational changes improves performance & 2.65 & 1.07 \\
Regular M\&E enables staff to handle assigned task thus improves performance & 3.68 & 1.11 \\
Targets in M\&E address the departments objective of enhancing national security & 3.88 & 0.90 \\
\hline Average Influence of Monitoring and Evaluation on Performance & $\mathbf{3 . 3 6}$ & $\mathbf{1 . 0 1}$ \\
\hline
\end{tabular}

Source: Researcher 2021

The findings show that the respondents were uncertain on whether monitoring and evaluation could influence performance (M3.36, SD 1.01). In particular, they were uncertain on whether frequent monitoring and evaluation had a positive influence on performance (M2.87, SD0.96). they we also uncertain on the use of feedback to bring operational changes (M2.65, SD 1.07). However, they seem to agree that following strict guidelines during monitoring and evaluation could influence performance (M3.37, SD1.03). They also agreed that regular monitoring and evaluation will improve performance (3.68 SD1.11). Finally setting targets in line with the departments main objective will improve performance (M3.88, SD 0.90)

\subsubsection{Effect of Delegation on Performance and National Security}

The third objective of the study was to investigate the effect of delegation on performance of immigration department, in enhancing national security in Kenya. Table 4 shows the results of this investigation.

Table 4: Effect of Delegation on Performance and National Security

\begin{tabular}{|lcc|}
\hline Delegation practices and Performance in relation to National Security & Mean & Std dev \\
\hline Giving discretionary powers can negatively influence performance & 2.78 & 1.13 \\
Subjecting suspects to many stages of interrogation can enhance performance & 3.23 & 1.13 \\
Allowing staff to perform task in the best way they think improves performance & 2.66 & 1.16 \\
accountability for decisions made by individuals positively influence performance & 3.47 & 1.14 \\
\hline Referring high risk cases to the supervisor will impact positively on performance & & \\
\hline
\end{tabular}


Source: Researcher 2021

The results show that the respondents were uncertain on the effects of delegation on performance and national security (M 3.00, SD1.15). In particular, they were uncertain on if discretionary powers could enhance performance (M2.78, SD1.13). They were also uncertain on influence of subjecting suspects to many stages of interrogation (M3.23, SD 1.13).

Respondents were also uncertain on if allowing staff to perform task in the best way they think could improve performance (M2.66, SD 1.16). Uncertainty was also shown on the impact of referring high risk cases to the supervisors (M 2.87, SD 1.15). However, the respondents agreed that making individuals be accountable for decision made positively influenced performance (M3.47, SD 1.14).

Influence of Strategic Partnership on Performance and National Security.

The forth objective was to assess the influence of strategic partnerships on the performance, of immigration department in enhancing national security in Kenya the results are shown is table 5

Table 5: Influence of strategic partnership on performance and national security.

\begin{tabular}{|lcc|}
\hline Influence of strategic partnership on performance and national security. & Mean & Std dev \\
\hline Structured information sharing mechanism will enhance performance & 3.87 & 1.12 \\
Performance will improve when all security agency work with mutual trust & 3.68 & 0.98 \\
sharing of intelligence gathered by other agencies will improve performance & 4.04 & 1.11 \\
involving immigration department in security meetings will improve performance & 4.01 & 0.96 \\
Competition and suspicion among security agents negatively affects performance & 3.96 & 1.15 \\
\hline Average influence of strategic partnership on performance & $\mathbf{3 . 9 1} \mathbf{1 . 0 6}$ \\
\hline
\end{tabular}

Source: Researcher 2021

According to the results, the respondents agreed that strategic partnership could positively influence performance (M3.91, SD 1.06). They agreed that structured information sharing will improve performance (M3.87, SD1.12). There was also an agreement that performance will increase if all agencies work with mutual trust (M3.68, SD 0.98). The respondents further agreed that performance will improve if intelligent information gathered by other departments is shared with immigration department (M4.04, SD 1.11). They also agreed that involving immigration department in security meetings will improve performance (M4.01, SD0.96). Finally the respondents agreed that performance had been negatively affected by suspicion and competition among the various security agencies, (M3.96,SD1,15) Multiple regression analysis was conducted so as to determine the relationship between the dependent variable (national security) and the four independent variables. As per the SPSS generated table 6.in the equation

$\mathrm{Y}=\beta_{0}+\beta_{1} \mathrm{X}_{1}+\beta_{2} \mathrm{X}_{2}+\beta_{3} \mathrm{X}_{3}+\beta_{4} \mathrm{X}_{4}+\varepsilon$

$\mathrm{Y}=$ Performance of Immigration Department $\mathrm{X}_{1}=$ Training

$\mathrm{X}_{2}=$ Monitoring and evaluation $\mathrm{X}_{3}=$ Delegation

$\mathrm{X}_{4}=$ Strategic partnership

$\beta_{0}=$ Is a constant (which is the value of dependent variable when all independent variables are zero)

$\beta_{1-4}$ is the regression coefficient or changes introduced by $X_{1}, X_{2}, X_{3}$ and $X_{4}$

$\varepsilon=$ Error term

The equation subsequently becomes:

$\mathrm{Y}+1.308+0.731 \mathrm{X}_{1}+0.620 \mathrm{X}_{2}+0.558 \mathrm{X}_{3}+0.785 \mathrm{X}_{4}$ 
The regression equation above has established that taking all factors into account that is training, monitoring and evaluation, delegation and strategic partnership between the immigration department and other state security agencies constant at zero employee's performance will be 1.308 .

The findings presented also show that taking all other independent variables at zero, a unit increase in staff training will lead to 0.731 increase of the departments contribution to national security. a unit increase in monitoring and evaluation will lead to 0.620 increase 
in the departments contribution to national security; a unit increase in delegation practices will lead to a 0.558 increase in the departments contribution to national security. and a unit increase in strategic partnership with other departments will lead to 0.785 increase in the departments contribution to national security. This infers that strategic partnership contributed most on the departments contribution to national security followed by training then monitoring and evaluation and delegation contributed the least.

At 5\% level of significance and $95 \%$ level of confidence, training had a 0.0285 level of significance; delegation showed 0.0276 level of significance: strategic partnership with other departments showed a 0.0202 level and monitoring and evaluation showed a 0.0249 level of significance hence the most significant factor

Table 6: Regression Coefficient

\begin{tabular}{|c|c|c|c|c|c|}
\hline \multirow[b]{2}{*}{\begin{tabular}{|l} 
Mode \\
(Constant)
\end{tabular}} & \multicolumn{2}{|c|}{$\begin{array}{l}\text { Unstandardized } \\
\text { Coefficients }\end{array}$} & \multicolumn{3}{|c|}{$\begin{array}{l}\text { Standardized } \\
\text { Coefficients }\end{array}$} \\
\hline & \begin{tabular}{|l|}
$\mathbf{B}$ \\
1.308
\end{tabular} & \begin{tabular}{|l} 
Std. Error \\
1.342
\end{tabular} & Beta & \begin{tabular}{|l|}
$\mathbf{T}$ \\
1.623
\end{tabular} & \begin{tabular}{|l} 
Sig \\
0.357
\end{tabular} \\
\hline Training & 0.731 & 0.156 & 0.210 & 3.532 & 0.285 \\
\hline Monitoring and evaluation & 0.620 & 0.245 & 0.148 & 3.458 & 0.0249 \\
\hline Delegation Practices & 0.558 & 0.310 & 0.172 & 4.342 & 0.0276 \\
\hline Strategic Partnership & 0.785 & 0.322 & 0.067 & 3.542 & 0.0202 \\
\hline
\end{tabular}

Source: Researcher 2021

\section{CONCLUSION}

Based on the findings, the study concluded that improved performance in the immigration department was key to enhanced national security. The study further concluded that improved performance could be achieved through proper implementation of some organization practices within the department.

The study concludes that when training is well structured by first identifying the need or the gap to be filled by the training it will lead to an improved performance. Also training should be well structured to ensure that all staff had an equal opportunity to attend to training. the study further concluded that training programme are not well structured in the department and therefore had not effectively played a role in improving performance.

The study also concluded that monitoring and evaluation was routinely done but the feedbacks were never used to develop and implement changes in the department. It was also noted that lack of a motivation strategy made the appraisal to be a mere procedural exercise rather than be a strategy to improve performance. The study therefore observed that if well implemented, monitoring and evaluation could have appositive impact on improved performance which will lead to enhancement in national security.

On delegation, the study observed that the department had very strict and rigid policy where the staff had very little impact in deciding how to better perform the assigned tasks. Also the department had little or no room for the staff to be more innovative and creative. This shortfall the study concluded that contributed negatively to the performance of the department and thus was a hindrance to its effectiveness in helping to improve national security.

Further the study realised that the environment of mistrust completion and constant blame game has been a major hindrance in the war on terrorism and other crimes associated with foreign nationals. From the study it was established with proper coordination and sharing of information, the departments will work as a team and thereby be able to greatly improve national security.

Finally, the study concluded that if the identified organization practices are well implemented in the department of immigration it will lead to improvement of the departments performance in relation to its objective of enhancing national security.

\section{Recommendations.}

Based on the above findings and conclusions the study recommends that the government should take initiative to improve on the organizational practices at the immigration department. This could be achieved through proper implementation of the identified organizational practices within the department of immigration.

The study further recommends that immigration department should be considered as one of the key players in national security. The department should therefore be involved in the security meetings at all levels for effective sharing of information which is key for any meaningful and effective war on terrorism.

This publication is licensed under Creative Commons Attribution CC BY.

http://dx.doi.org/10.29322/IJSRP.11.11.2021.p11926 
The study recommends that the government should be in a position to create an environment in which the departments work in harmony rather than the competition and

blame game witnessed in the past terror attacks and create a team work approach with one agenda of fighting terrorism

Finally, the study recommends that training should be well structured to ensure it meets the goals of the equipping the staff with the required skills to match the changes in the environment. And also ensure that important practices such as monitoring and evaluation are not done merely as routine practices but should be aimed at ensuring that feedbacks are obtained and used to improve on service delivery.

\section{Suggestions for Further Study.}

The study investigated the organizational practices at the department of immigration and their influence on improvement of performance in the department. This study mainly focused on the role played by the staff. The researcher therefore suggests that further studies should be done focusing on other critical areas that have a direct influence on the organizations performance in meeting its goal. Further studies should therefore focus on issues such as policy and technology and their contribution to improving the performance of immigration department. And the other gaps identified in the discussion on each of the objectives.

\section{REFERENCES}

[1] Agnew, R. and Timothy, B. Ed. (2010). Strain theories handbook of criminological theory. London SAGE: Eugine McLaughlin and TM Newbuin.

[2] Amen, I. (2013). The effects of training on employee performance. European Journal of Business and Management, Vol 15 (4)

[3] Atellah, E. (2019). An Anatomy of Terrorist Attacks in Kenya. New Africa Magazine February 2019

[4] Blair, E. (2013 October 4th) Kenya intelligence work hurt by corruption, rivalries among security agencies. Business Daily Africa.

[5] Bennett, B. (2011 June 12th) Al Qaeda operatives key to 1998 U.S. embassy bombings killed in Somalia. Los Angeles Times.

[6] Chauli, S.S. (2003). The politics of refugee hosting in Tanzania from open doors to unsustainability, insecurity and receding receptivity. Journal of refugee studies Vol $16(2)$

[7] Chepkiloti, R.K. (2012). Motivational strategies for public sector workers in Kenya. International Journal of research in management. Vol 2 (2).

[8] CIDA (2001). Result based management in CIDA: An introductory guide to concepts and principles.

[9] Clemens, M.A. (2011). Economics of emigration; the trillion-dollar bills on the side walk. Journal of economic perspective. Vol 25 (3).

[10] Clemens, M.A. (2016). The new economic case for migration restriction: an assessment. Journal of economic perspective. Vol 45 (7).

[11] Cohen, A. and Sayag, G. (2010). The Effectiveness of Internal Auditing: An Empirical Examination of its Determinant s in Israeli Organizations. Australian accounting review. Vol 20 (3)

[12] Cooper, D.R. and Schindler, P.S. (2003). Business research methods, 9th Edition. McGraw Hill Publishing, Co. Ltd. New Delhi India.

[13] Corrine, G. (2011). Becoming a quantitative researcher: An introduction, 4th Edition. Pearson. Boston U.S.A.

[14] Dinkelman, T. and Mariotti, M. (2015). The long run effect of labour migration on human capital in communities of origin. American economic journal of applied economics. Vol 8(4).

[15] Durkheim, E. (1951). Suicide: A study in sociology. New York Free Press. (Original work published in 1897).

[16] Giovano, J. Levchenko, A. and Ortega, F. (2015). A global view or cross border migration. Journal of European economics. Vol 13(1).

[17] Government of Kenya (2003). Economic recovery strategy for wealth creation and employment creation. Nairobi: government press.

[18] Government of Kenya (2005). Information booklet on performance contracting in the public service. Nairobi: directorate of personnel management.

[19] Government of Kenya (2012) National Monitoring and Evaluation Policy. Nairobi: Ministry of Planning, National Development and Vision 2030.

[20] Hasim, T.A. Ahmed, A. and Jaradat, N. (2013). The impact of structural empowerment in achieving psychological empowerment in Jordanian public organizations. Journal of Hebron University for research. Vol 8 (1)

[21] International center for migration policy development. (2008). East Africa migration route initiatives: gaps and needs analysis, project country reports. I.C.M.P.D. Viena, Austria.

[22] International organization for migration (I.O.M. 2008). Human trafficking in eastern Africa: research assessment and baseline information in the united republic of Tanzania, Kenya, Uganda, and Burundi. I.O.M. Geneva, Switzerland.

[23] International organization for migration (I.O.M. 2016). A report on migration trends in

[24] Kenya and the role of immigrants on the Kenyan economy. I.O.M Nairobi, Kenya.

[25] Jiang, K. Lepak, D. Hu, J. And Baer, J. (2012). How does human resource management influence organizational outcome? A meta-analytic investigation of mediating mechanism. Academy of management journal. Vol 55(6).

[26] Kenya Anti-Corruption Commission (2006). An examination report on the systems, policies procedures and practices at the ministry of immigration and registration of persons. Nairobi: government press.

[27] Kobia, M. and Mohammed, N. (2006). The Kenya experience with performance contacting: Discussion paper, 28th AAPAM conference Arusha Tanzania 4th - 8th December 2006. 
International Journal of Scientific and Research Publications, Volume 11, Issue 11, November 2021

ISSN 2250-3153

[28] Kombo, D.K. and Tromp, D.L.A. (2011). Proposal and thesis writing, and introduction.

Nairobi: Pauline's publication Africa.

[29] Mbai, C.O. (2003). Public service accountability and governance in Kenya since independence. African association of political science. Vol 8 (1).

[30] Mbijjiwe, J.M. and Venkataiah, P. (2013). The doom of employees 'training in public service. Case Study of Ministry of Education in Kenya. Journal of Business and Management 14(2).

[31] Merton, R.K. (1957). Social theory and social structures. Revised ed. New York: free press.

[32] Mugenda, O. and Mugenda, A. (2003). Research methods, quantitative and qualitative approaches. Nairobi: ACTS press.

[33] Mohamed, Y. (2019 January 22nd). Calm restored after a deadly terror attack at the Dusit D2 complex. Daily nation.

[34] Mutanda, J.M. (2017). An overview of performance contracting in Kenya's public sector, benefits and challenges. Imperial journal of interdisciplinary research. Vol $3(1)$.

[35] Obong'o, S.O. (2009). Implementation of performance contracting in Kenya. Internal public management review. Vol 10 (2).

[36] OPM/PSTD (2010). Public Sector Transformation Strategy: From Reform to Transformation.2010-14. Office of the Prime Minister/ Public Sector Transformation Department. Nairobi. Government printers.

[37] Orodho, A.J. (2005). Essentials of education and social science research methods. Nairobi.

Masalo publishers.

[38] Orodho, A.J. and kombo, D.K. (2002). Research methods. Nairobi. Kenyatta university institute of open learning.

[39] Ousey, G.C. and Kubrin, C.E. (2018). Immigration and crime; assessing a contentious issue. Journal of annual review of criminology. Vol 17 (5).

[40] Peterson, R. Krivo, L. and Hagan, J. (2006). The Many Colors of Crime: inequalities of race, ethnicity and crime in America. New York and London: New York University Press.

[41] President Uhuru Kenyatta, September 24, 2013, Address by Kenyan head of state to the nation after Westgate attack available at http://www.statehousekenya.

[42] Regional Mixed Migration Secretariat. (2013). A mixed migration in Kenya; the scale of movement and associated protection risks. RMMS. Nairobi. Kenya.

[43] Stivatchts, Y. (2008). International migration and the politics of identity and security. Journal of humanities and social sciences. Vol 2 (1).

[44] Tai, W.T. (2006). Effects of training framing, general self-efficacy and training motivation on trainees training effectiveness. Emerald group publishers.

[45] United States Department of States (2017). A report on the use of PISCES to counter terrorism in Kenya. Nairobi: US Embassy.

[46] Warren, P.Y. and Thomakovic, D.D. (2009). Racial profiling and searches. Did the policy of racial profiling change police behavior? Journal of criminology and public policy. Vol 8(2)

\section{AUTHORS}

First Author - Ms. Victoria K. Avoga, Student, Department of Management, school of business and economics mount kenya university,Po Box 342-01000,Thika Kenya vavoga2011@gmail.com

Second Author - Dr Isaac Mokono Abuga. Phd, Lecturer Department of economics, school of business and economics mount kenya university,Po Box 342-01000,Thika Kenya isaacabuga81@ gmail.com 